\title{
Late-life mental disorders and primary health care
}

\author{
BRIAN COOPER
}

The primary health-care setting represents the middle ground of psychiatric epidemiology (Shepherd \& Wilkinson, 1988) and confers advantages for research in terms of case-definition, case-finding, population coverage and the representative nature of the picture it can give of psychiatric illness in the wider community. Studies based on general-practice populations should not be regarded as substitutes for area fieldsurveys, but can supplement these and at the same time increase the opportunities for a research input to health-service planning and practice. So far, investigations in this field have been largely concentrated on the disorders of early and middle adult life, few studies having been devoted to the elderly. Research priorities are, however, beginning to change as the populations of developed countries grow older and the mental disorders of late life - in particular, dementia and affective disorders - become increasingly prevalent.

It has in the past been widely assumed that general practitioners are unable to exploit their innate advantages in this field because of a failure to identify many cases of mental disorder presenting among their elderly patients. One widely-cited British study, for example, concluded that only one in five cases of late-life dementia were known to the patients' own doctors (Williamson et al. 1964). Although there is little information about corresponding rates for detection of depression among the elderly, surveys of adult patients more generally have indicated a failure to recognize somewhere between one-third and half

Indirizzo per la corrispondenza: Professor B. Cooper, Abt. Epidemiologische Psychiatrie, Zentralinstitut für Seelische Gesundheit, Postfach 122 120, W-6800 Mannheim, Germany.

Fax (+49) 0621-234.29. of clinically significant depressive states (Blacker \& Clare, 1987).

In recent years, the practitioners' diagnostic sensitivity seems to have increased, at any rate in some countries, although the evidence is still fragmentary and in part conflicting. Thus, research projects in general practice in the U.K. (O'Connor et al., 1988) and Germany (Cooper \& Bickel, 1990) have reported much higher rates of case-recognition for dementia, while MacDonald (1986) found that doctors in three London practices tended to over-diagnose depression in the elderly, only one in eight of all disagreements between the psychiatrist's and the practitioner's assessments arising because cases had been missed by the latter. On the other hand, a recent study in Australian general practice revealed a low medical sensitivity to the presence either of dementia or of depression (Bowers et al., 1990). Such disparities may reflect different stages in a general trend, whose stage of advance varies from country to country.

The widespread assumption that most practising physicians are insensitive to mental abnormality in their elderly patients has influenced research workers to turn more and more to standardized screening procedures, which they assume to be more accurate and in some sense more "scientific» than the doctors' clinical assessments. Screening instruments which have been designed to detect dementia by simple tests of memory and cognitive performance, such as the Mini Mental State Examination, have been employed in primary-care settings (Bowers et al., 1990; lliffe et al., 1989). The detection of depressive states presents somewhat different requirements, since these conditions often present with somatic complaints, and the underlying emotional distress may have to be 
elicited by systematic questioning. Standardized complaint inventories have proved valuable in detection of depression and other functional mental disorders among adult patients, and the General Health Questionnaire, in particular, has been widely applied as a screening method in the primary-care setting (Marino et al., 1990). Few such methods, however, have been standardized for use in elderly populations.

While the findings obtained with standardized screening methods are undoubtedly more reliable (in terms of reproducibility) than those based on clinical judgment, and this is advantageous in research, their employment in medical practice suffers from a number of drawbacks. They may be too unspecific for the detection of early and mild cases; they do not permit scoring and assessment of incomplete responses; they raise problems of acceptability and patient compliance, and cannot readily be incorporated into the practice routine, or adapted for ongoing case monitoring. A method of case-detection is required that can be applied under the conditions of day-to-day practice, can deal with anomalous responses and can make use of collateral information from patients' relatives, community nurses or other sources: in short, a clinical diagnostic approach, but one which makes use of standard guidelines.

The practising physician's interest in early casedetection will grow once he becomes convinced that this can lead to effective forms of intervention, and hence to an improvement in his patients' clinical prognosis (Sanson-Fisher \& Hennrikus, 1988). Guidelines are needed, with respect to case-detenction and diagnosis, but also to subsequent case-management. The physician needs to know, first, which special investigations are called for, and how intensively these should be pursued. Secondly, there is the issue of specialist referral and liaison. Rates of referral to psychiatric out-patient services tend to decline in the higher age-groups, a trend unrelated to age-specific prevalence curves. No doubt other factors are involved, including the system of specialist referral and the general practitioners' often low expectations of their elderly patients. In the UK an alternative to hospital referral has developed since the 1960s, in which psychiatrists make regular visits to group general practices and work directly with the primary-care team (Williams \& Balestrieri, 1989). While «outreach» strategies of this kind are potentially important for the elderly mentally ill, they are not easy to implement. Experience suggests that the old people will usually be given low priority by psychiatric services, whatever the mode of referral, unless there is some degree of specialization in their problems. There is thus a strong case for setting up psychogeriatric teams, a large part of whose work will be centred in the community, and will include a consultative service to primary care professionals (Cooper, 1992). But psychogeriatricians are few in number in most countries, and this makes direct liaison with the general practitioners difficult, especially if many of the latter are still in single-handed practice. Experience gained in local innovative schemes could be of great value in pointing to ways of achieving better-integrated forms of care provision in the future.

Finally, the general practitioner requires guidance on treatment and management of the many mentally ill old people who cannot be dealt with by specialist services. So far, most attention in research has been directed to the question of pharmacotherapy. Far more psychotropic medication is known to be prescribed by general practitioners than by psychiatrists (Beardsley et al., 1988), but there is uncertainty about the usefulness of much of this treatment for the elderly, especially with regard to the so-called "cognition enhancers" or "nootropica», whose clinical value in cases of dementia or even milder states of cognitive decline is highly questionable, but which are still being prescribed extensively. The use of antidepressant medication in the elderly also calls for firmer clinical indications and more systematic monitoring. Some improvement in national prescribing patterns may be achieved with the help of largescale collaborative programmes of the kind now being sponsord in the USA by the National Institute of Mental Health, and in the UK jointly by the Royal Colleges of Psychiatrists and General Practitioners.

But the general practitioner's therapeutic role is by no means restricted to prescribing psychotropic drugs: there is also a great need for supportive medical care, undertaken in conjunction with community nursing and social-work agencies, and calling for cooperation with voluntary workers and self-help groups. The growth of multidisciplinary teamwork affords new opportunities for support to family caregivers, many of whom suffer in their own health and emotional state from the burden of caring tasks, the loss of an intimate personal relationship caused by the mental deterioration, and the curtailment of their own earning power and social activities (Morris et $a l ., 1988)$. The physician can help to sustain their morale by explanation and encouragement, by making home visits and by mobilizing social agencies 
(Philp \& Young, 1989). Practice-attached nurses, if equipped with simple diagnostic guidelines, are able to assess the mental health status of old persons they visit at home, and can thus bring to light many undeclared cases of mental decline. Such attachment schemes are an important step towards anticipatory («proactive») care for the elderly, though they do not automatically ensure its development. A future goal in evaluative research must be to assess the efficacy of this and other forms of comunity care, by means of controlled comparative studies (Cooper, 1990).

In a recent review of the social psychiatry of late life, Henderson (1990) proposed that one outstanding research priority should be «studies of the contribution of general practice to the care of mental disorders in the elderly, and how to improve that contribution». There are compelling arguments in support of this conclusion, to which need only be added that the studies concerned should include within their scope epidemiological inquiries into the occurrence and distribution of psychogeriatric illness, as well as into its early detection and diagnosis in the community.

\section{REFERENCES}

Beardsley R. S., Gardocki G. J,, Larson D. B. \& Hidalgo J. (1988). Prscribing of psychotropic medication by primary care physicians and psychiatrists. Archives of General Psychiatry 45, 1117-1119.

Blacker C. V. R. \& Clare A. W. (1987). Depressive disorders in primary care. British Journal of Psychiatry 150, 737-751.

Bowers J., Jorm A. F., Henderson S. \& Harris P. (1990). General practitioners' detection of depression and dementia in elderly patients. Medical Journal of Australia 153, 192-196.

Cooper B. (1990). Strategia di ricerca epidemiologica nella valutazione dei servizi di salute mentale. In La Valutazione in
Psichiatria (a cura di W. Di Munzio), pp. 125-147. Liguori: Napoli.

Cooper B. (1992). Late-life mental disorders and primary health care: a review. In Primary Health Care and Psychiatric Epidemiology (ed. B. Cooper and B. Eastwood), pp. 213-233. Tavistock/Routledge: London.

Cooper B. \& Bickel H. (1990). Early detection of dementia in the primary care setting. In The Public Health Impact of Mental Disorder (ed. D. Goldberg and D. Tantam), pp. 166-175. Hogrefe-Huber: Göttingen.

Henderson A. S. (1990). The social psychiatry of later life. British Journal of Psychiatry 156, 645-653.

Iliffe S., Booroff A., Gallivan S., Goldenberg E., Morgan P. \& Harries A. (1990). Screening for cognitive impairment in the elderly, using the Mini Mental State Examination. British Journal of General Practice 40, 277-279.

MacDonald A. J. D. (1986). Do general practitioners «miss» depression in elderly patients? British Medical Journal 292, 1365-1368.

Marino S., Bellantuono C. \& Tansella M. (1990). Psychiatric morbidity in general practice in Italy. A point-prevalence survey in a defined geographical area. Social Psychiatry and Psychiatric Epidemiology 25, 67-72.

Morris R. G., Morris L. W. \& Britton P. G. (1988). Factors affecting the emotional wellbeing of the caregivers of dementia sufferers. British Journal of Psychiatry 154, 147-156.

O'Connor D. W., Pollitt P. A., Hyde J. B., Brooke C. P. B., Reiss B. B. \& Roth M. (1988). Do general practitioners miss dementia in elderly patients? British Medical Journal 297, 1107-1110.

Philp I. \& Young J. (1988). Audit of support given to lay carers of the demented by a primary care team. Journal of the Royal College of General Practitioners 38, 153-155.

Sanson-Fisher R. W. \& Hennrikus D. J. (1988). Why do primary care physicians often fail to detect psychological disturbance in their patients? In Handbook of Social Psychiatry (ed. A. S. Henderson and G. Burrows), pp. 245-256. Elsevier: Amsterdam.

Sheppherd M. \& Wilkinson G. (1988). Primary care as the middle ground for psychiatric epidemiology. Editorial. Psychological Medicine 18, 263-267.

Williams P. (1985). Le ricerche epidemiologiche sui disturbi psichiatrici nella medicina di base: una rassegna della letteratura. In L'Approccio Epidemiologico in Psichiatria (ed. M. Tansella), pp. 321-340. Torino: Boringhieri.

Williams P. \& Balestrieri M. (1989). Psychiatric clinics in general practice. Do they reduce admissions? British Journal of Psychiatry 154, 67-71.

Willamson J. Stokoe I. H., Gray S., Fisher M., Smith A., McGhee A. \& Stephenson E. (1964). Old people at home: their unreported needs. Lancet $1,1117-1120$. 


\section{Cesario Bellantuono, Michele Tansella}

\section{Gli psicofarmaci \\ nella pratica terapeutica}

Seconda edizione

Un libro di 416 pagine. Lire 55.000

Presentazione di A. Balestrieri

Prefazione di S. Garattini

Questo volume, che riporta i risultati delle ricerche più recenti apparse nella letteratura internazionale, da un lato sottolinea l'importanza di un uso razionale degli psicofarmaci, dall'altro mette in evidenza la necessità di considerare tale uso all'interno della pratica terapeutica complessiva dei Servizi e degli operatori psichiatrici. Il volume, giunto alla seconda edizione, notevolmente ampliata e modificata rispetto alla prima, è stato scritto pensando soprattutto agli psichiatri in formazione ed agli psichiatri che vogliano rimanere aggiornati in un settore, come quello della psicofarmacologia, in costante progresso ed evoluzione.

Compilate e spedite in busta chiusa a:

\section{Il Pensiero Scientifico Editore}

$\square$ SI DESIDERO RICEVERE ${ }^{\circ}$ "Gli psicofarmaci nella pratica terapeutica" al prezzo di Lire 55.000 la copia VERSERỎ LA SOMMA DI LIRE

$\square$ VERSAMENTO C/C POSTALE N ${ }^{\circ} 902015$
$\square$ VISA
$\square$ CARTASÌ
$\square$ MASTERCARD

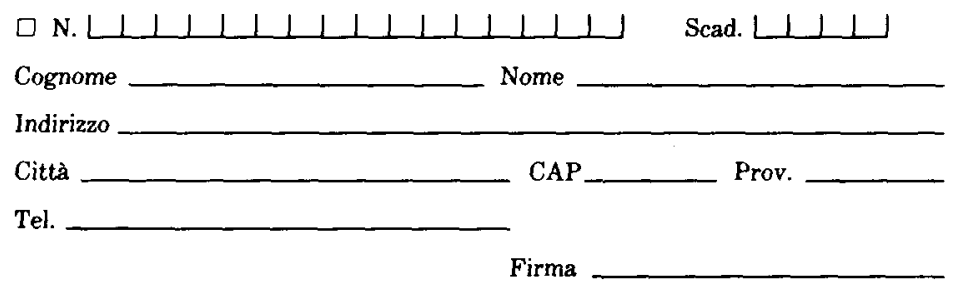

